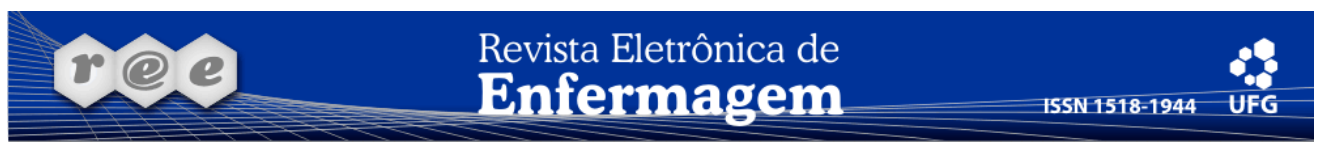

Artigo Original

\title{
Diagnóstico de enfermagem: integridade tissular prejudicada identificado em idosos na Estratégia de Saúde da Família ${ }^{1}$
}

\author{
Nursing diagnosis impaired tissue integrity identified in elderly patients in the Family Health Strategy \\ Diagnóstico de enfermería: deterioro de la integridad tisular identificada en ancianos, \\ en la Estrategia de Salud de la Familia
}

\author{
Agueda Maria Ruiz Zimmer Cavalcante ${ }^{\mathrm{I}}$, Ariana Moreira ${ }^{\mathrm{II}}$, Kétila Barros de Azevedo ${ }^{\mathrm{III}}$, \\ Luciano Ramos de Lima ${ }^{\mathrm{VI}}$, Wanessa de Kássia Alves Melo Coimbrav

\footnotetext{
${ }^{1}$ Trabalho de conclusão do curso de graduação em Enfermagem.

${ }^{\text {I } E n f e r m e i r a . ~ M e s t r e ~ e m ~ E n f e r m a g e m . ~ D o c e n t e ~ d a ~ U n i E V A N G E ́ L I C A . ~ A n a ́ p o l i s, ~ G O, ~ B r a s i l . ~ E-m a i l: ~ e n f ~ a q u e d a @ y a h o o . c o m . b r . ~}$

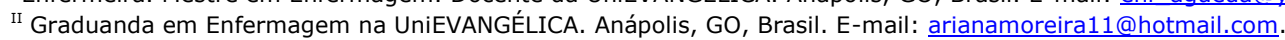

III Graduanda em Enfermagem na UniEVANGÉLICA. Anápolis, GO, Brasil. E-mail: ketilabarros@hotmail.com.

IV Enfermeiro. Mestre em Enfermagem. Docente da UniEVANGÉLICA. Anápolis, GO, Brasil. E-mail: enframosil@gmail.com

vEnfermeira. Anápolis, GO, Brasil. E-mail: enf wanessamelo@yahoo.com.br.
}

\section{RESUMO}

A exposição da pele a agentes agressivos implica no aparecimento de feridas que comprometem o bem estar. Em idosos, pode levar ao adoecimento e instalação de agravos que reduzirão a qualidade de vida. A avaliação do enfermeiro ao portador de feridas revela-se essencial e visa promover condições de adequada cicatrização dos tecidos. Este estudo objetivou identificar a ocorrência de integridade tissular prejudicada, os tipos de feridas mais frequentes e os produtos utilizados para o tratamento. Estudo descritivo, quantitativo, realizado em 2009, com 27 idosos portadores de integridade tissular prejudicada, cadastrados em estratégias de saúde da família de um município do interior de Goiás. Foram realizadas consultas de enfermagem com avaliação do estado de saúde e da ferida. Mediante análise dos dados identificou-se que 74,0\% dos idosos eram do sexo feminino, 70,3\% tinham entre 60 a 69 anos e 33,3\% eram casados. 0 tipo de ferida mais frequente foi a úlcera venosa $(66,6 \%)$. Os participantes apresentaram até três patologias associadas, sendo que $66,6 \%$ eram portadores de diabetes e $55,5 \%$ de insuficiência venosa. O AGE consistiu no produto mais utilizado pelos indivíduos. A avaliação criteriosa do enfermeiro contribui para um planejamento coerente com as necessidades da população e atuação segura do enfermeiro.

Descritores: Diagnóstico de enfermagem; Idoso; Cicatrização de feridas.

\section{ABSTRACT}

The skin exposition to aggressive agents results in the appearance of wounds that commit the well being of patients. In the elderly, this may lead to sickening and installation of hazards that will reduce the life quality of this population. The nurse's evaluation of a patient who presents skin wounds reveals itself essential and aims the promotion of adequate conditions to the tissue's healing process. This research had as objective identify the occurrence of impaired tissue integrity, the most frequent types of wounds and the products used in treatment. Descriptive and quantitative study, in which took part 27 elderly patients with impaired tissue integrity, all registered in family health strategies of a municipality in the state of Goias in 2009. An evaluation of the health and wound status was made during nursing consults. Through the analysis of data it was identified that $74,0 \%$ of the patients were female, $70,3 \%$ were between 60 to 69 years-old and 33,3\% were married. Most frequent type of wound was the venous ulcer $(66,6 \%)$. The participants presented up to the associated pathologies, in such a way that $66,6 \%$ had diabetes and $55,5 \%$ had venous insufficiency. The most utilized product by the patients was the AGE. The nurse's criterious evaluation contributes to a planning made according to the population 's needs and safe actuation of the nursing professional.

Descriptors: Nursing diagnosis; Elderly; Wound healing.

\section{RESUMEN}

La exposición de la piel a agentes agresivos tiene como consecuencia la aparición de heridas que comprometen el bienestar. En ancianos puede llevar a la enfermedad y a la instalación de molestias que reducen la calidad de vida de esa población. La evaluación que el enfermero efectúa sobre el portador de heridas se revela esencial y tiene como objetivo promover condiciones de adecuada cicatrización de los tejidos. La pesquisa tuvo como objetivo identificar el deterioro de la integridad tisular, los tipos de heridas mas frecuentes y los productos utilizados para el tratamiento. Estudio descriptivo, cuantitativo, realizado en 2009, en 27 ancianos portadores de deterioro en la integridad tisular, cadastrados en estrategias de salud de la familia del municipio en el estado de Goiás. Fueron realizadas consultas de enfermería con evaluaciones del estado de salud y de la herida. A través del análisis de los datos, se identifico que 74,0\% de los ancianos eran del sexo femenino, $70,3 \%$ tenían entre 60 y 69 años y 33,3\% estaban casados. El tipo de herida mas frecuente fue la úlcera venosa (66,6\%). Los participantes presentaron hasta tres patologías asociadas, siendo que $66,6 \%$ eran portadores de diabetes y $55 \%$ de insuficiencia venosa. El AGE fue el producto mas utilizado por los individuos. La evaluación cuidadosa del enfermero contribuye para una planificación coherente con las necesidades de la población y para la actuación segura del enfermero.

Descriptores: Diagnóstico de enfermería; Anciano; Cicatrización de heridas. 


\section{INTRODUÇÃo}

As diversas funções da pele podem ser alteradas na presença de lesões incapacitantes e de difícil cicatrização. O surgimento dessas lesões pode ser determinado em razão da exposição a diversos fatores. A resposta imunológica do organismo desempenha um papel importante a fim de combater agentes etiológicos que comprometem o funcionamento adequado desse extenso órgão. Contudo, tal resposta estará reduzida durante o envelhecimento, comprometendo a saúde do indivíduo. A pele torna-se frágil, seca, rígida e rugosa, perdendo a elasticidade e a capacidade de atuar como barreira contra fatores extrínsecos ${ }^{(1-2)}$.

O envelhecimento traz consigo um perfil de risco para as doenças crônicas, especialmente as cardiovasculares, respiratórias e metabólicas que podem contribuir para 0 aparecimento de feridas como úlceras arteriais, úlceras diabéticas, úlceras venosas, úlceras por pressão, dentre outros $^{(3)}$. Essas enfermidades crônicas aumentam as incapacidades funcionais e cognitivas dos idosos, o número de internações hospitalares e comprometem significativamente a qualidade de vida desta população ${ }^{(4-5)}$.

Estudo realizado com 40 idosos atendidos em uma unidade de estratégia de saúde da família na cidade de Goiânia demonstrou que $50 \%$ dos sujeitos apresentavam a integridade da pele prejudicada evidenciada pela presença de lesões como escoriações, eritemas e descamações. Essas alterações de pele são desencadeadas por fatores coadjuvantes como extremos de idade, fatores imunológicos, alterações do turgor, metabolismo alterado, diminuição da sensibilidade, estado nutricional alterado, entre outros, que desencadeiam no idoso uma menor resistência às infecções e diminuição da imunocompetência tissular contribuindo para o aparecimento de lesões na pele mais profundas e comprometedoras e com o tempo de reparação tissular retardado(6).

Outro estudo realizado com intuito de identificar os diagnósticos de enfermagem mais comuns na clínica médica de um hospital escola no estado de São Paulo demonstrou que para o domínio segurança/proteção o diagnóstico mais frequente foi integridade tissular prejudicada com 63,3\%. Acredita-se que tal diagnóstico quando comparado à integridade da pele prejudicada, ambos os presentes no domínio segurança/proteção, representa maiores comprometimentos à saúde do indivíduo. Em se tratando de idosos, tal comprometimento poderá reduzir significativamente a autonomia, capacidade funcional, e aumentar o tempo de internação desta população(3).

De acordo com a classificação dos diagnósticos de enfermagem da NANDA-I, a integridade tissular prejudicada define-se como: "dano às membranas mucosas, córnea, pele ou tecidos subcutâneos" podendo estar associado à circulação alterada, déficit de conhecimento, déficit de líquidos, excesso de líquidos, extremos de temperatura, fatores nutricionais, irritantes químicos, mecânicos (pressão, abrasão, fricção), mobilidade física

prejudicada e radiação, evidenciados por tecido destruído e tecido lesado (córnea, mucosas, pele ou tecidos subcutâneos) que levam à perda da integridade tissular e comprometimento da sua função fisiológica(7).

O cuidado dispensado ao portador de integridade tissular prejudicada na estratégia saúde da família contribui para a redução de agravos e complicações desencadeadas pela presença do diagnóstico. Portanto, cabe ao enfermeiro uma assistência integral e contínua que vise um tratamento adequado, assistência aos demais fatores que interferem no processo cicatricial, orientações e ações educativas que vão ao encontro das necessidades dessa população. O cuidado com lesões na pele e tecidos adjacentes, ainda na atenção primária, pode minimizar os riscos de aparecimento de complicações em indivíduos, diminuir o número de internações e consequente gastos públicos, contribuir para a visibilidade e valorização das ações do enfermeiro junto ao idoso $^{(8-9)}$

A assistência ao portador de lesões de pele, assim como as diversas formas de tratamento, exige do enfermeiro um conjunto de estratégias que possibilitem o alcance precoce dos objetivos propostos, por meio da sistematização da assistência de enfermagem. Ao utilizar os sistemas de classificação dos diagnósticos de enfermagem durante a assistência, o enfermeiro poderá oferecer cuidados que correspondam às reais necessidades do indivíduo favorecendo uma assistência holística, além de planejar cuidados que busquem o alcance de metas e resultados visíveis ${ }^{(1)}$.

Por acometer grande parte da população idosa do país, as lesões de pele constituem-se um sério problema epidemiológico que merece atenção exclusiva por parte dos profissionais de saúde por meio de cuidados multidisciplinares, possibilitando uma redução dos agravos e possíveis desencadeadores desse processo, melhoria na qualidade de vida dessa população, além de demonstrar resolutividade dos serviços de saúde, principalmente, na atenção primária.

Este estudo teve como objetivo identificar a ocorrência do diagnóstico de enfermagem integridade tissular prejudicada de acordo com a Taxonomia da NANDA-I em idosos portadores de feridas, inseridos na Estratégia de Saúde da Família de um município do interior de Goiás, identificar os tipos de feridas mais frequentes entre os portadores, bem como os produtos utilizados para o tratamento das lesões.

\section{MÉTODO}

Trata-se de uma pesquisa descritiva, de abordagem quantitativa, realizada com idosos cadastrados nas unidades de Estratégia de Saúde da Família (ESF) de um município do interior de Goiás.

Do total de 31 unidades de ESF presentes no município, foram realizadas visitas a 28 dessas, das quais 14 continham pacientes idosos portadores de feridas. Considera-se que a contratação recente de profissionais para as unidades dificultou na identificação desses sujeitos, demonstrando uma subnotificação dos casos de feridas em idosos. A amostra foi composta por 27 idosos portadores de feridas com idade igual ou superior a 60 anos. Os critérios de inclusão na pesquisa foram: aceitar participar da pesquisa por meio da assinatura do Termo de Consentimento Livre e Esclarecido; ser idoso (60 anos ou mais); ser portador de lesões na pele e tecidos adjacentes; apresentar o diagnóstico de enfermagem integridade tissular prejudicada; e estar cadastrado na Estratégia de Saúde da Família de um município do interior de Goiás. Foi determinada como critério de exclusão a terceira visita consecutiva ao domicílio do paciente, mesmo após agendamento prévio e o mesmo não ter sido encontrado em casa. 
Após serem esclarecidos sobre a pesquisa, os idosos concordaram em participar do estudo e assinaram o Termo de Consentimento Livre e Esclarecido (TCLE), de acordo com a Resolução 196/96 do Conselho Nacional de Saúde, relativa à pesquisa envolvendo seres humanos, o qual recebeu parecer favorável pelo Comitê de Ética em Pesquisa da UniEVANGÉLIVA em agosto de 2009 com número de protocolo 0068/2009.

Foram realizadas visitas às unidades de saúde, seguindo uma lista de ESF cadastradas pela secretaria de saúde do município, a qual continha o nome e endereço de cada unidade. Posteriormente, foi realizada uma busca no banco de prontuários das unidades, além de entrevista informal junto à equipe de enfermagem visando identificar moradores portadores de lesões. A partir da identificação dos sujeitos foi realizado o agendamento das visitas domiciliares conforme a disponibilidade dos agentes comunitários de saúde (ACS) e do próprio cliente.

A coleta de dados foi realizada em um ambiente privativo no domicílio de cada idoso ou no consultório de enfermagem da ESF no qual o sujeito era cadastrado, no período de agosto a outubro de 2009, mediante o preenchimento de um instrumento de coleta de dados elaborado pelos pesquisadores e fundamentado na literatura científica. Este continha aspectos relacionados ao perfil sociodemográfico, de saúde e doença, hábitos alimentares, tempo de existência das feridas, principais produtos utilizados e características das lesões. Foi realizado exame clínico e embora não fosse objetivo deste estudo, os pesquisadores assistiram cada participante conforme as necessidades e diagnósticos de enfermagem identificados.

Para a análise dos resultados obtidos foram utilizados procedimentos de estatística descritiva e elaboração de tabelas utilizando recursos do programa Excel.

\section{RESULTADOS E DISCUSSÃO}

Durante a coleta de dados, observou-se um elevado número de cadastros de idosos nas unidades de saúde, porém poucos prontuários continham informações sobre a presença de lesões. Alguns prontuários não continham a informação, porém durante a visita observou-se a presença de feridas. Por outro lado, detectou-se ausência de informações relativas ao estado de saúde dos indivíduos por parte da equipe que os assistiam.

Foram visitados 62 idosos, porém apenas 27 (64,28\%) enquadraram-se nos critérios de inclusão. A Tabela 1 representa o perfil sociodemográfico dos idosos participantes da pesquisa.

Tabela 1: Caracterização do perfil sociodemográfico dos idosos portadores de feridas e cadastrados na ESF de um município do interior de Goiás, 2009. $(n=27)$.

\begin{tabular}{|c|c|c|}
\hline Características & $\mathbf{N}$ & $\%$ \\
\hline \multicolumn{3}{|l|}{ Idade } \\
\hline Idoso jovem (60 a 69 anos) & 19 & 70,2 \\
\hline Idoso velho (70 a 79 anos) & 6 & 22,3 \\
\hline Idoso muito velho ou muito idoso ( $>80$ anos) & 2 & 7,5 \\
\hline \multicolumn{3}{|l|}{ Sexo } \\
\hline Feminino & 20 & 74,0 \\
\hline Masculino & 7 & 26,0 \\
\hline \multicolumn{3}{|l|}{ Estado Civil } \\
\hline Casado & 9 & 33,3 \\
\hline Solteiro & 8 & 29,7 \\
\hline Viúvo & 7 & 26,0 \\
\hline Divorciado & 3 & 11,0 \\
\hline \multicolumn{3}{|l|}{ Escolaridade } \\
\hline Analfabeto & 15 & 55,6 \\
\hline 10 grau incompleto & 10 & 37,0 \\
\hline 10 grau completo & 1 & 3,7 \\
\hline $2^{\circ} \mathrm{grau}$ completo & 1 & 3,7 \\
\hline
\end{tabular}

Dos 27 idosos que participaram do estudo $20(74,0 \%)$ eram do sexo feminino e sete $(26,0 \%)$ do sexo masculino. A idade variou de 60 a 86 anos, sendo que 19 (70,2\%) tinham entre 60 e 69 anos e oito $(29,8 \%)$ tinham idade igual ou superior a 70 anos. Desses, nove $(33,3 \%)$ eram casados e $18(66,7 \%)$ eram solteiros, viúvos e divorciados. Quanto à escolaridade $15(55,6 \%)$ eram analfabetos e 12 $(44,4 \%)$ tinham algum grau de escolaridade.

As feridas tiveram maior prevalência no sexo feminino (20) correspondendo a $74,0 \%$ da população estudada. Os dados corroboram para a feminização do envelhecimento. Este fenômeno pode ser justificado pelo fato das mulheres apresentarem mais atenção ao aparecimento de problemas de saúde e maior utilização dos serviços de saúde. As características podem estar relacionadas à maior expectativa de vida das mulheres, implicando em fragilidade, incapacidade e dependência ${ }^{(10)}$.
Conforme Martins e Souza as mulheres são mais propensas ao aparecimento de feridas devido a fatores hormonais e menopausa ${ }^{(11)}$.

Estes fatores juntamente com o uso contínuo de anticoncepcionais e de medicamentos para reposição hormonal durante a menopausa podem gerar o aparecimento de varizes em mulheres ainda jovens que, com o decorrer do tempo, provoca obstrução de veias e hemorragias espontâneas ou traumáticas, ocasionando lesões, principalmente nos membros inferiores, dificultando o retorno venoso. Além disso, o envelhecimento e o número de gestações são importantes fatores para o desenvolvimento de feridas ${ }^{(12)}$.

Estudo realizado em uma unidade básica de saúde (UBS) no interior do Rio Grande do Sul constatou que $78 \%$ dos portadores de feridas eram do sexo masculino, o que diverge dos dados deste estudo. Este dado pode ser 
justificado pelo fato da população estudada no Rio Grande do Sul ter idade mínima de 18 anos, possuir baixo índice de escolaridade o que contribui para a baixa adesão ao mercado de trabalho formal. Acredita-se que essa faixa etária encontra-se mais susceptível à ocorrência de acidentes e traumas que levam ao surgimento de lesões ${ }^{(13)}$.

Observa-se que a alta prevalência de feridas no sexo feminino nas unidades de saúde pesquisadas ocorre devido a uma busca aumentada a esses serviços em comparação com o sexo oposto, o que demonstra ainda a possibilidade de existência de feridas também no sexo masculino; inferese que estes casos podem estar subnotificados em determinadas unidades.

A prevalência das feridas em idosos com idade entre 60 a 69 anos foi predominante $(70,2 \%)$ em relação às idades mais avançadas, podendo ser observado com o declínio precoce e acentuado das funções orgânicas e consequente diminuição da qualidade de vida. Acredita-se que o retardo na busca pelos serviços de saúde contribui para a manifestação de agravos na fase inicial da velhice $^{(9,13)}$.

Outro aspecto importante a ser considerado refere-se ao alto índice de idosos solteiros, viúvos e divorciados $(66,7 \%)$, comparados àqueles que mantinham união estável. No que diz respeito ao estado civil, estudos apontam que idosos casados apresentam melhor saúde devido ao maior suporte do companheiro e ao cuidado que não receberiam estando solteiros. Por outro lado, os idosos viúvos e solteiros tem maior probabilidade de se tornarem independentes. Apresentam um padrão de vida diferente, alimentação mais pobre, piores condições econômicas, maior uso de medicações em longo prazo, além de viverem sozinhos e na maioria das vezes, isolados. Contudo, apesar das expectativas, este grupo possui menos dificuldades do que os idosos que vivem com o cônjuge, os quais se tornam mais independentes para realizar determinadas atividades, podendo influenciar no prolongamento do declínio funcional e mental ${ }^{(4)}$.

Com relação à escolaridade, destaca-se o alto índice de analfabetos $(55,6 \%)$ que se mostra superior à soma das demais escolaridades referidas pelo grupo pesquisado. $O$ analfabetismo pode estar associado à deficiência educacional dessa geração, o que reflete diretamente no autocuidado com a saúde, na busca de auxílio dos profissionais, relacionado ao pouco conhecimento sobre os agravos de saúde, sinais e sintomas, inclusive na dificuldade em compreender a linguagem usada por profissionais, comprometendo o tratamento necessário(14-15).

Estudo realizado com idosos de uma equipe da Estratégia de Saúde da Família (ESF) da cidade de GoiâniaGO, que também caracterizou o perfil sócio demográfico e de saúde do idoso, demonstrou predominância do sexo feminino (54,3\%), da faixa etária de 60 a 69 anos (58,0\%), do analfabetismo $(53,3 \%)$, porém o número de idosos casados $(50,5 \%)$ mostrou-se divergente do encontrado neste estudo ${ }^{(9)}$.

Em se tratando da presença de lesões de pele e tecidos adjacentes observa-se a carência de instruções que prejudicam na compreensão das orientações sobre os cuidados desempenhados, já que exige do indivíduo o conhecimento de suas patologias que podem surgir se não tratados conforme orientação dos profissionais da saúde. Além disso, deve-se levar em conta as crenças desses idosos frente às práticas de saúde sobre diversos tipos de substâncias como formas terapêuticas, as quais são perpetuadas e que prejudicam o processo cicatricial, podendo lesar ainda mais o ferimento, e dificultar na adesão ao tratamento adequado ${ }^{(4-5)}$.

É importante ressaltar que a presença do enfermeiro assistencial na atenção primária pode minimizar os riscos de aparecimento de agravos à saúde em idosos jovens, levando à prevenção de complicações e à promoção da saúde. É indispensável que o profissional de saúde esteja mais atento a indivíduos nessa faixa etária, prestando maiores cuidados e aperfeiçoando a sua ação junto à equipe e aos agentes de saúde, pois é comum entre a população em foco certa resistência na adesão ao tratamento e medidas preventivas que a ajudem na manutenção da saúde ${ }^{(8-9)}$.

As úlceras crônicas, principalmente de etiologia vasculogênica tem se tornado um importante problema de saúde no nosso meio. Um dos aspectos relevantes e que contribuem para a explicação desse fenômeno é o envelhecimento populacional. As úlceras de perna constituem uma das patologias mais frequentes nos ambulatórios dos hospitais e em consultórios ${ }^{(10,14)}$. Levando em consideração os tipos de lesões encontradas nessa população, nota-se que o quantitativo de úlceras ultrapassa o número de idosos participantes, já que um paciente apresentou mais de um tipo de úlcera (Tabela 2).

Tabela 2: Tipos de feridas presentes nos idosos portadores do diagnóstico de enfermagem integridade tissular prejudicada, em um município do interior de Goiás, 2009.

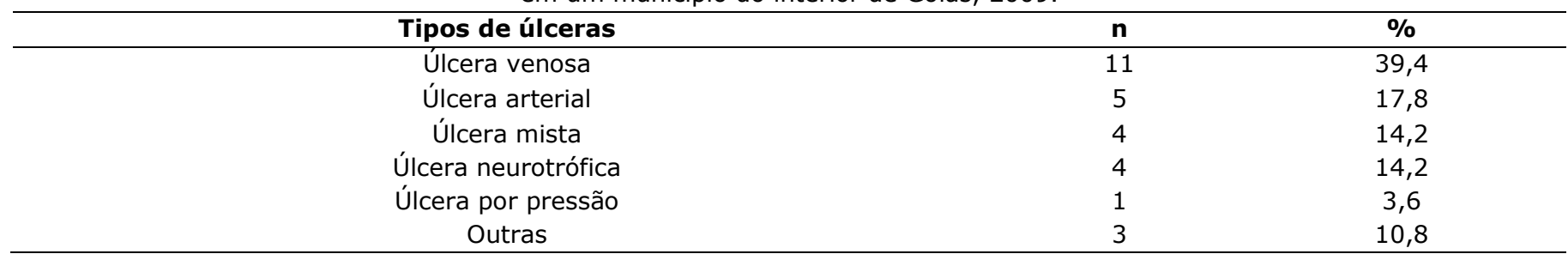

O tipo de úlcera mais comum encontrado na população estudada foi a úlcera venosa $(39,4 \%)$, caracterizada por alterações físicas da pele e do tecido subcutâneo como edema, hiperpigmentação, eczema, erisipela, lipodermatosclerose, principalmente nos membros inferiores, especificamente nos maléolos distais ${ }^{(1)}$.
Os membros inferiores são os locais mais comumente acometidos por diversos tipos de úlceras, pelo fato de estarem intensamente mais expostos a traumas e por apresentarem uma circulação contra a gravidade em decorrência da postura ereta do ser humano(12-13).

A insuficiência venosa é definida pelo mau funcionamento do sistema venoso podendo ser causada por 
uma obstrução venosa associada ou não a varizes, má formação valvular, oclusão por coágulo gerando uma sobrecarga do fluxo sanguíneo e dificultando o retorno venoso, o qual irá desencadear uma hipertensão venosa. Com o tempo essa pressão elevada afeta a microcirculação, causa danos às paredes dos vasos, aumenta a permeabilidade dos mesmos e permite a liberação de substâncias do seu interior para a pele, ocasionando alterações cutâneas, além da deficiência no suprimento de oxigênio e nutrientes nas regiões dos membros inferiores, o que provoca um processo inflamatório e aumenta a susceptibilidade de ulcerações e necroses nessas regiões $^{(4,12)}$.

As úlceras venosas desencadeiam-se de forma espontânea ou traumática, em tamanho e profundidade variáveis, com recidivas frequentes. Estudos demonstram que este tipo de úlcera atinge mais o sexo feminino (75\%) comparado ao masculino (25\%), devido a fatores ligados a maior longevidade. Salienta-se a importância de se considerar os fatores predisponentes e causadores desse tipo de úlcera, para implementação do tratamento tópico e compressivo. Sem a devida compreensão desse fator e a utilização adequada de terapia compressiva, a hipertensão venosa não poderá ser controlada e consequentemente os efeitos patológicos da insuficiência venosa aumentarão ${ }^{(1,11,16)}$.

A frequência das demais úlceras (Tabela 2) comparada às úlceras venosas mostrou-se inferior, correspondendo a cinco $(17,8 \%)$ de úlceras arteriais, quatro $(14,2 \%)$ mistas, e quatro $(14,2 \%)$ neurotróficas, uma $(3,6 \%)$ por pressão, e três $(10,8 \%)$ referente a outros tipos de úlceras.

As úlceras arteriais são decorrentes da doença arterial periférica que afeta as artérias de grande, médio e pequeno calibre, principalmente pela aterosclerose, leva a obstrução progressiva das artérias, desencadeia isquemia, diminui o fluxo sanguíneo e consequentemente a diminuição de nutrientes e oxigênio ao leito da ferida contribuindo para a cronicidade das úlceras devido à dificuldade no processo cicatricial. Sua localização é mais frequente no maléolo lateral e no calcâneo ${ }^{(1)}$.

Observa-se que as úlceras venosas e arteriais possuem grande importância entre as feridas crônicas, sendo responsável por um significativo índice de morbimortalidade da população. As úlceras venosas com componente arterial (úlceras mistas) são comuns e mais difíceis de tratar ${ }^{(4,11)}$.

O aparecimento de úlceras neurotróficas ocorre a partir de neuropatias periféricas geralmente associadas a doenças vasculares, principalmente em pacientes diabéticos, que possuem uma maior tendência em apresentar lesões ulceradas nos pés, pela diminuição da sensibilidade nos membros inferiores, tornando-os vulneráveis a esse tipo de lesão ${ }^{(17)}$.

As inúmeras lesões de pele que afetam os idosos são apontadas por diversos estudos, com incidências distintas relacionando o ambiente como fator somatório à integridade tissular prejudicada. A prevalência de feridas em idosos constatada em ambiente hospitalar caracterizou-se por predomínio das úlceras por pressão (44\%), seguidas de $11 \%$ de úlceras neurotróficas, e $1 \%$ de úlcera mista ${ }^{(10)}$. Este alto índice de úlcera por pressão está intimamente ligado ao aumento de internações e reinternações relacionado às doenças de longa duração e ao próprio sistema imunológico do paciente idoso ${ }^{(9,15)}$.
Nota-se que os tipos de feridas evidenciados neste estudo estão diretamente associados ao fator relacionado "circulação alterada". Observa-se ainda que o cliente com o diagnóstico de integridade tissular prejudicada apresenta características relevantes de outros diagnósticos de enfermagem que também remetem a importância do cuidado com feridas e irá contribuir positivamente para o tratamento e a diminuição de recidivas e de internações frequentes.

Todos os participantes da pesquisa eram portadores do diagnóstico de enfermagem integridade tissular prejudicada $(100 \%)$, pois apresentavam lesões caracterizadas como profunda ou total, quando a lesão atinge, além das camadas superiores, o tecido subcutâneo, músculo e ossos ${ }^{(1)}$. As características definidoras referentes a este diagnóstico de enfermagem são evidenciadas por tecidos destruídos e tecidos lesados(7).

Destacam-se outros diagnósticos que podem ser identificados em idosos: mobilidade física prejudicada, deambulação prejudicada, dor aguda e crônica, integridade da pele prejudicada, risco de infecção, isolamento social, déficit no autocuidado, nutrição desequilibrada para mais ou para menos do que as necessidades corporais, risco de desequilíbrio do volume de líquidos, conhecimento deficiente, risco de tensão do papel de cuidador $^{(3,9,15)}$. Os outros diagnósticos de enfermagem identificados nesses clientes idosos portadores do diagnóstico integridade tissular prejudicada podem tornar-se fator relacionado do diagnóstico em estudo e contribuir para o raciocínio clínico e tomada de decisão do enfermeiro visando a excelência do cuidado prestado.

Se, por um lado, o envelhecimento populacional trouxe os benefícios de uma maior longevidade, por outro, trouxe um novo perfil de morbi-mortalidade, caracterizado por um aumento de doenças crônicas não transmissíveis ${ }^{(14-15)}$. Tendo em vista os agravos de saúde dos portadores do diagnóstico em foco, foi notória nos 27 participantes a presença de uma ou mais patologias que desencadeiam lesões ou contribuem para o retardo do processo cicatricial (Tabela 3). 
Tabela 3: Distribuição da amostra em relação aos agravos de saúde em idosos de ESF com feridas, em um município do interior de Goiás, 2009.

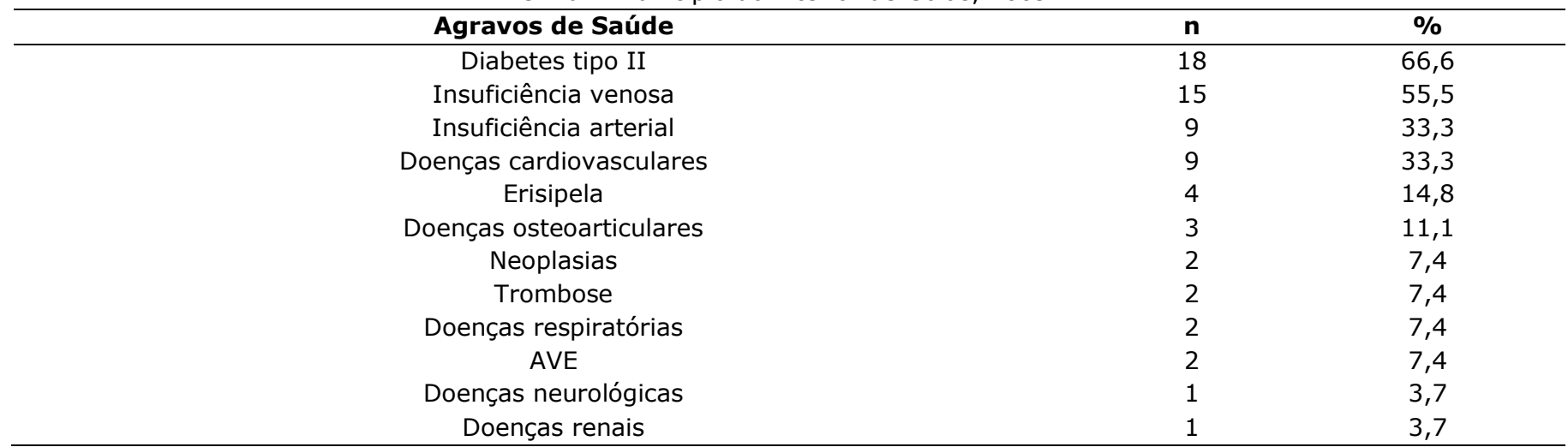

Em relação à extensão, as feridas foram classificadas em pequenas $\left(<5,0 \mathrm{~cm}^{2}\right)$, médias $\left(5,1\right.$ a $\left.20,0 \mathrm{~cm}^{2}\right)$, grandes $\left(20,1\right.$ a $\left.50,0 \mathrm{~cm}^{2}\right)$ e extensas ( $\left.50,0 \mathrm{~cm}^{2}\right)$. Destaca-se que as feridas médias foram frequentes em $40 \%$ dos clientes estudados, as feridas pequenas em $25,71 \%$, as extensas em $22,85 \%$, e as grandes em menor proporção $11,42 \%$. A maioria dos clientes $(62,8 \%)$ possuía feridas com profundidade de $0,5 \mathrm{~cm}$, seguidas por feridas que variavam de 0,6 a $1,0 \mathrm{~cm}(31,4 \%)$ e as profundas, de $1,1 \mathrm{a}$ $2,0 \mathrm{~cm}$, que tiveram pouca representação entre os participantes $(5,7 \%)$.

É importante considerar que seis $(22,3 \%)$ participantes apresentaram mais de uma ferida em membros diferentes, - que demonstra a ausência de cuidados e a falta de informação que a população tem devido a essas feridas, seus fatores de risco e patologias comprometedoras. O não uso de produtos adequados a cada estágio de cicatrização, a falta de acompanhamento por um profissional capacitado, e o não tratamento da patologia de base dificulta o processo cicatricial e favorece o surgimento de novas lesões, além de aumentar o tempo de existência da ferida tornando-a mais complexa, incapacitante e difícil de tratar ${ }^{(18-19)}$.

O fator relacionado que interferiu diretamente no aparecimento da integridade tissular prejudicada foi a circulação alterada demonstrada pelos agravos de saúde apresentados na Tabela 3. Considera-se que o processo de envelhecimento traz consigo alterações biológicas que diminuem a capacidade do idoso em manter a homeostasia quando submetido a um estresse fisiológico. Há uma diminuição do desempenho intelectual, memória e capacidade de resolução de problemas, e limitação da capacidade de proteção e cuidado da própria pele, aumentando os níveis de incapacidades, limitando as tarefas básicas de auto cuidado que normalmente são necessárias para uma vida independente na comunidade ${ }^{(6,10,15)}$.

De uma forma geral, o declínio da área motora resultante do processo fisiológico, como também, da falta de atividade física regular, e hábitos de vida, acarretarão em atrofia da musculatura e articulações, e desencadearão fatores relacionados como a mobilidade física prejudicada, comprometendo a circulação, principalmente dos membros inferiores, aumentando as chances de ocorrência de quedas e consequentemente de lesões ${ }^{(9,15)}$. Essas alterações justificam a ocorrência dos agravos de saúde presentes nos participantes e evidenciados na Tabela 3, tendo ênfase no diabetes mellitus, nas insuficiências arteriais e venosas e doenças cardiovasculares ${ }^{(10,12)}$.
As alterações metabólicas evidenciadas principalmente pelo diabetes mellitus contribuem para fragilidade cutânea, aumentando o risco de desenvolvimento de lesões à medida que as complicações decorrentes da progressão da patologia surgem. A neuropatia diabética, nas suas várias condições, desencadeia perda da sensação dolorosa, tátil e de pressão, alterações no formato dos pés, predispondo o indivíduo ao risco de ulcerações frequentemente em membros inferiores. Entretanto, o próprio processo de envelhecimento favorece alterações metabólicas, que culminam em modificações fisiológicas, as quais variam entre os indivíduos ${ }^{(1,17)}$.

O impacto e a interferência negativa em ser diabético e ter pé ulcerado na vida das pessoas são notáveis. Sabe-se que pessoas com diabetes e doença cardiovascular têm maior risco de recorrência da doença e pior resposta ao tratamento proposto, uma vez que se têm duas doenças crônicas de difícil controle, pois ambas exigem mudanças bruscas no estilo de vida, além de apresentarem complicações importantes ${ }^{(5)}$.

O sistema cardiovascular se torna deficiente devido a inúmeros distúrbios cardíacos e vasculares, principalmente por meio da aterosclerose e obstruções arteriais e venosas, que geram diminuição do fluxo sanguíneo circulante, principalmente nos membros inferiores, levando ao surgimento de lesões e retardo cicatricial que facilita a ocorrência de embolias, tromboses e infartos. Em alguns pacientes, a arteriosclerose associa-se à microangiopatia diabética, acarretando menor fluxo tissular, com consequentes menor oxigenação e menor pressão de perfusão local ${ }^{(16)}$.

A ocorrência de trombose pode ser influenciada pelo tabagismo, visto que a nicotina age como um vasoconstritor que reduz o fluxo sanguíneo para a pele, resultando em isquemia tissular, além de aumentar a aderência plaquetária, favorecendo a ocorrência de trombose e consequentemente o aumento dos riscos de aparecimento de lesões tissulares que atingem camadas profundas do tecido subcutâneo ${ }^{(4,11)}$.

Verificou-se neste estudo que seis $(22,2 \%)$ dos portadores de feridas são tabagistas, um $(3,7 \%)$ etilista, um $(3,7 \%)$ refere que parou de beber e/ou fumar em um espaço de tempo menor que um ano, 10 (37,03\%) em um espaço de tempo maior que 30 anos, e nove (33,37\%) nunca beberam e/ou fumaram.

Estudos mostram que em pacientes tabagistas nota-se uma cicatrização retardada, pois o ato de fumar reduz a hemoglobina funcional e causa disfunção pulmonar, 
predispondo a privação da oxigenação no sangue e no tecido subcutâneo causando hipóxia tecidual. Já o alcoolismo pode ocasionar lesões no cérebro, coração, fígado e pâncreas, interferindo na adesão ao tratamento e também no funcionamento cognitivo e comportamental do ser humano(11-12).

Percebe-se nesse estudo que o cliente com o diagnóstico de enfermagem integridade tissular prejudicada desenvolve lesões em virtude da circulação alterada, da mobilidade física prejudicada, fatores mecânicos e déficit de conhecimento, tais fatores são corroborados com a literatura que fundamenta este diagnóstico.

Considera-se o envelhecimento populacional e o aumento da expectativa de vida fatores coadjuvantes na prevalência de doenças crônicas e incapacitantes que geralmente não admitem cura e, se não forem devidamente tratadas e acompanhadas ao longo dos anos, tendem a apresentar complicações que comprometem a independência e a autonomia do indivíduo. Dessa forma, compete ao profissional da área da saúde esclarecer ao cliente as devidas informações sobre a patologia e complicações, além de orientar quanto aos hábitos de vida saudáveis e acompanhamentos constantes que promovam saúde e previna agravos.
O cuidado com feridas tem sido registrado desde os tempos antigos, pelos egípcios e gregos, estando intimamente ligado a costumes e hábitos populares. Até a década de 70, acreditava-se que a cicatrização era mais satisfatória quando o leito da ferida apresentava-se seco(2). Atualmente estudos contestam a utilização do curativo seco, comprovando que a manutenção do meio úmido no leito da ferida e a cobertura do mesmo favorecem e aumentam a velocidade de cicatrização.

Estudos demonstram que a cicatrização do meio úmido acelera a angiogênese, estimula a epitelização e a formação do tecido de granulação, facilita a remoção de tecido necrótico e fibrina, atua como barreira protetora contra microorganismo, promove a diminuição da dor, e ainda evita traumas na troca do curativo ${ }^{(19)}$.

Os avanços tecnológicos têm possibilitado a utilização de produtos que aceleram a cicatrização e facilitam a vida do portador de lesões. A Tabela 4 representa a variedade dos produtos utilizados pelos indivíduos da pesquisa, sendo que a somatória dos produtos ultrapassa o número de participantes devido ao uso concomitante de alguns produtos.

Tabela 4: Principais produtos utilizados pelos idosos portadores de feridas, em um município do interior de Goiás, 2009.

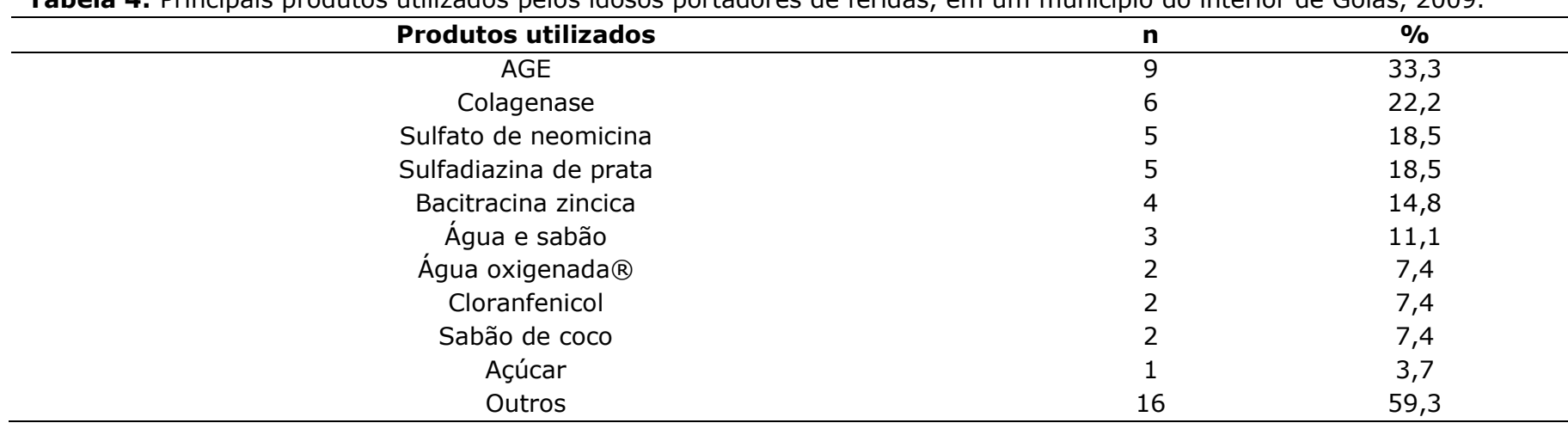

Neste estudo identificaram-se múltiplos produtos utilizados pelos participantes e também a ausência de produtos. Obtiveram maior frequência o AGE, mais conhecido pelos participantes como dersani ${ }^{\circledR}(33,3 \%)$, a colagenase $(22,2 \%)$, o sulfato de neomicina $(18,5 \%)$, e a sulfadiazina de prata $(18,5 \%)$.

Destaca-se o uso frequente do AGE (pertencente à classe dos ácidos graxos essenciais - AGE derivados do ácido linoléico) pela população alvo. Tal substância utilizada é indicada na prevenção e tratamento de dermatites, úlceras de pressão, venosa e neurotrófica, tratamento de úlceras abertas com ou sem infecção. Auxilia no desbridamento autolítico é bactericida para $S$. aureus, e de aplicação diária ${ }^{(15,19)}$.

Embora o uso de AGE no tratamento de feridas seja amplamente utilizado no Brasil, encontram-se poucos estudos sobre sua utilização. Porém não foram identificados estudos que tenham obtido resultados que contra-indiquem o uso de $A G E$, ou que não recomendam o seu uso ${ }^{(16)}$.

Os compostos enzimáticos são utilizados em muitos curativos promovendo o desbridamento das lesões. Entre as enzimas mais usadas podemos citar a colagenase (enzimas isoladas) que age desbridando de forma suave os tecidos desvitalizados. Não deve ser utilizada em feridas com cicatrização por primeira intenção (quando há aproximação das bordas) ou em pacientes sensíveis aos compostos. A troca é feita a cada 24 horas $^{(19)}$.

A sulfadiazina de prata tem função bactericida imediata e bacteriostática, devido aos sais de prata. É indicada na prevenção de colonização e tratamento de queimadura. A troca deve ser feita a cada 12 horas. É de fácil uso e baixo custo $^{(15)}$.

O uso de antibióticos locais como neomicina, bacitracina, gentamicina, dentre outros podem desenvolver a resistência bacteriana e ainda induzir reações de hipersensibilidade. Além disso, deve-se levar em consideração que frequentemente a troca de curativos é realizada pelo próprio indivíduo ou por cuidadores que não dominam a técnica do curativo e acabam por ocasionar traumas, provocado por limpeza agressiva, coberturas secas aderidas ao leito da ferida e inadequadas ${ }^{(15,19)}$.

Foi notório neste estudo o uso indiscriminado de diversos produtos populares como açúcar, vaselina, álcool e fumo, glicerina, iodopovidine. Além de dificultar o processo cicatricial, agride a pele íntegra, trazendo complicações ainda mais sérias. $O$ uso de açúcar pode funcionar como meio de cultura para bactérias patogênicas. Atualmente, o tratamento com este produto está restrito às feridas limpas 
com troca a cada duas horas. O PVPI tópico deve ser padronizado apenas para anti-sepsia da pele íntegra, podendo provocar reações alérgicas e adversas além de impedir ou retardar o processo de cicatrização ${ }^{(16,18)}$.

A variedade de produtos utilizados pelos portadores de feridas sem o acompanhamento contínuo de um profissional da área da saúde dificulta o processo de cicatrização. Um estudo realizado no interior de Minas Gerais em portadores de úlcera varicosa demonstrou que o tempo médio da presença da ferida é de 10 anos. Este fato foi relacionado com a falta de atendimento profissional em determinados dias, o uso de substâncias inadequadas para o tratamento, condições ambientais de higiene inadequadas e o tempo prolongado na realização de atividades prejudiciais (deambulação), para esses pacientes. Outro fato relevante é que na maioria dos casos, o início do tratamento no domicílio e a procura dos profissionais da área da saúde ocorrem em última instância comprometendo a cicatrização da ferida ${ }^{(18)}$.

A cicatrização de feridas consiste em um perfeito e coordenado conjunto de fases fisiológicas e bioquímicas para a reconstituição do tecido lesado. Para que este processo ocorra é necessário que os fatores sistêmicos (idade, biótipo, doenças crônicas, condições nutricionais, ineficiências vasculares, imunossupressão e radioterapia) e locais (pressão, ambiente seco, trauma, edema, infecção, necrose, incontinência e hábitos de vida diários tabagismo/alcoolismo) estejam em harmonia para propiciar a formação de colágeno, angiogênese, epitelização e contratura da ferida ${ }^{(1-2)}$.

O sucesso no tratamento de feridas depende da competência e do conhecimento dos profissionais envolvidos, de sua capacidade de avaliação e de selecionar técnicas e recursos disponíveis. A avaliação geral do cliente deve levar em conta não apenas a lesão a ser tratada, mas o portador com suas características e necessidades, estabelecendo assim um planejamento que instigue 0 paciente ao autocuidado. É importante ressaltar a dependência dos portadores de lesões de cuidadores familiares ou profissionais. Isso se dá, principalmente, devido às falhas de educação e insegurança para o autocuidado $^{(2,19)}$.

Estudos revelam que cerca de $40 \%$ dos indivíduos com 65 anos ou mais necessitam de algum tipo de ajuda para realizar tarefas como fazer compras, cuidar das finanças, preparar refeições e limpar a casa. Uma parcela menor $(10 \%)$ requer auxílio para realizar tarefas básicas como tomar banho, vestir-se, ir ao banheiro, alimentar-se, sentar e levantar de cadeiras e camas. Esses dados remetem a figura do cuidador que surge por vários motivos, inclusive em decorrência ao acometimento de agravos e complicações na saúde ${ }^{(8,15)}$.

O enfoque do tratamento do portador de feridas é realizado na perspectiva de que o paciente ou o eventual cuidador leigo saiba cuidar da ferida. É de responsabilidade do profissional enfermeiro não só esclarecer, mas fazer com que $o$ individuo enxergue que os hábitos de vida adquiridos podem influenciar negativamente (sedentarismo, dieta desequilibrada e falta de atividade física) como futuros desencadeadores e também como dificultadores do processo de cura.

\section{CONCLUSÃO}

A integridade tissular prejudicada foi evidenciada em 27 idosos pesquisados. As lesões eram caracterizadas por tecidos lesados ou destruídos, atingindo camadas mais profundas como músculos e ossos. O fator relacionado que possuiu papel coadjuvante no aparecimento de lesões foi a circulação alterada, sendo justificado pela presença das patologias: diabetes mellitus tipo II e insuficiências venosas e arteriais.

Observou-se uma grande variedade de produtos $e$ soluções cicatrizantes no tratamento das feridas, destacando-se o uso frequente do AGE $(33,3 \%)$ devido seu baixo custo e fácil acesso. Entre outros produtos utilizados destacam-se ainda, a colagenase $(22,2 \%)$, o sulfato de neomicina e a sulfadiazina de prata $(18,5 \%)$.

Mediante estes achados, pode-se concluir que este fenômeno merece maior atenção do enfermeiro na tentativa de coibir tratamentos empíricos comprovadamente prejudiciais no processo de cicatrização, como a utilização do açúcar, álcool, fumo, PVPI tópico e outros. Acredita-se que o enfermeiro contribua na seleção de produtos adequados a partir da identificação precoce de diagnósticos de enfermagem, implementando cuidados que se direcionam as necessidades reais da clientela assistida, visando a redução de custos e a minimização de complicações advindas como resultado de tratamento ineficazes, promovendo orientações, implementando ações de prevenção e melhorando a qualidade de vida desta clientela.

\section{REFERÊNCIAS}

1. Silva RCL, Figueiredo IBM, Meireles IB. Feridas: fundamentos e atualizações em enfermagem. São Caetano do Sul, SP: Yendis; 2007.

2. Malaquias SG, Bachion MM, Nakatani AYK. Risco de integridade da pele prejudicada em idosos hospitalizados. Cogitare Enferm [internet]. 2008; 13(3):428-36. Available from:

http://www.revenf.bvs.br/pdf/ce/v13n3/a15v13n3.pdf.

3. Fontes CMB, Cruz DALM. Diagnósticos de enfermagem documentados para pacientes de clínica médica. Rev. Esc. Enf. USP. 2007;41(3):395-402.

4. Carmo SS, Castro SD, Rios VS, Sarquis MGA. Atualidades na assistência de enfermagem a portadores de úlcera venosa. Rev. Eletr. Enf. [Internet]. 2007;9(2):506-17. Available from: http://www.fen.ufg.br/revista/v9/n2/v9n2a17.htm

5. Amaral AS, Tavares DMS. Cuidados com os pés: conhecimento entre pessoas com diabetes mellitus. Rev. Eletr. Enf. [Internet]. 2009;11(4)801-10. Available from: http://www.fen.ufg.br/revista/v11/n4/pdf/v11n4a05.pdf.

6. Resende DM, Bachion MM, Araújo LAO. Integridade da pele prejudicada em idosos: estudo de ocorrência numa comunidade atendida pelo Programa de Saúde da Família. Acta Paul. Enferm. 2006;19(2):168-73.

7. North American Nursing Diagnosis Association (NANDA). Diagnósticos de enfermagem da NANDA: definições e classificação - 2007-2008. Porto Alegre: Artmed, 2008. 393 p.

8. Diogo $M J^{\prime} E$, Duarte YAO Cuidados em domicílio: conceitos e práticas. In: Freitas EV et al. Tratado de geriatria e gerontologia. $2^{a}$ edição. Rio de Janeiro: Guanabara Koogan; 2006.p. 1122-30. 
9. Nakatani AYK, Silva LB, Bachion MM, Nunes DP. Capacidade funcional em idosos na comunidade e propostas de intervenção pela equipe de saúde. Rev. Eletr. Enf.[Internet]. 2009;11(1):144-50. Available from: http://www.fen.ufg.br/revista/v11/n1/v11n1a18.htm.

10. Parahyba MI, Veras R, Melzer D. Incapacidade funcional entre as mulheres idosas no Brasil. Rev. Saúde Pública [Internet]. 2005;39(3): 383-391. Available from: http://www.scielo.br/pdf/rsp/v39n3/24791.pdf

11. Martins DA, Souza AM. O perfil dos clientes portadores de úlceras varicosa cadastrados em programas de saúde pública. Cogit. Enf. [Internet]. 2007;12(3):353-7. Available from:

http://ojs.c3sl.ufpr.br/ojs2/index.php/cogitare/article/view/ $10032 / 6891$.

12. Moura RMF, Gonçalves GS, Navarro TP, Britto RR, Dias RC. Correlação entre classificação clínica ceap e qualidade de vida na doença venosa crônica. Rev. bras. Fisioter. [Internet]. 2010. Available from: http://www.scielo.br/pdf/rbfis/2010nahead/aop007 10.pdf 13. Millão LF, Ellensohn L, Paczkoski RF, Ferreira MN, Pedroso M. Perfil dos portadores de feridas no território de abrangência da Unidade Básica de Saúde. União Logos. 2006;17(1):5-10.

14. Carboni RM, Reppetto MA. Uma reflexão sobre a assistência à saúde do idoso no Brasil. Rev. Eletr. Enf. [Internet]. 2007;9(1):251-60. Available from: http://www.fen.ufg.br/revista/v9/n1/v9n1a20.htm.

15. Menezes TMO, Lopes RLM, Azevedo RF. A pessoa idosa e o corpo: uma transformação inevitável. Rev. Eletr. Enf. [Internet]. 2009;11(3):598-604. Available from: http://www.fen.ufg.br/revista/v11/n3/v11n3a17.htm.

16. Jorge SA, Dantas SRPE. Abordagem multiprofissional do tratamento de feridas. São Paulo: Atheneu; 2005.

17. Secretaria de Políticas Públicas, Ministério da Saúde. Manual de condutas para úlceras neurotróficas e traumáticas. Brasília (Brasil): Ministério da Saúde, 2002. 56 p.

18. Martins DA, Souza AM. O perfil dos clientes portadores deúlceras varicosas cadastrados em programas de saúde pública. Cogitare Enferm. 2007; 12 (3): 353-7. Available from:

http://www.revenf.bvs.br/pdf/ce/v12n3/v12n3a11.pdf.

19. Franco D, Gonçalves LF. Feridas cutâneas: a escolha do curativo adequado. Rev. Col. Bras. Cir. [Internet]. 2008;35(3):203-6. Available from: http://www.scielo.br/pdf/rcbc/v35n3/a13v35n3.pdf.

Artigo recebido em 14.12.2009

Aprovado para publicação em 16.06.2010

Artigo publicado em 31.12.2010 